$\geq$ MCID at week 12 compared with PBO. Similarly, more pts receiving TCZ-SC reported scores $\geq$ normative values at week 12 compared with PBO, despite few pts with such scores at baseline. Responses were similar between pts treated with TCZ-SC and TCZ-IV + csDMARDs in SUMMACTA at week 24. These data show TCZ treatment resulted in clinically meaningful improvements in PROs and indicate that attainment of normative scores is a realistic goal in treatment of pts with active RA.

References:

[1] Kivitz A, et al. Arthritis Care Res (Hoboken). 2014;66:1653-61.

[2] Burmester G, et al. Ann Rheum Dis. 2014;73:69-74.

Acknowledgements: This study was funded by F. Hoffmann-La Roche/Genentech.

Disclosure of Interest: V. Strand Consultant for: Abbvie; Amgen; AstraZeneca; Biogen Idec; Boehringer Ingelheim; Celltrion; Crescendo; Genentech/Roche; GlaxoSmithKline; Janssen; Lilly; Merck; Novartis; Pfizer; Regeneron; Samsung; Sanofi; UCB, K. Lampl Employee of: Genentech, Inc, C. Birchwood Employee of: Genentech, Inc, J. Pei Employee of: Genentech, Inc, K. Tuckwell Shareholder of: Roche, Employee of: Roche, R. Finch Shareholder of: Roche, Employee of: Roche, A. Kivitz Consultant for: Genentech; Novartis; Pfizer; Sanofi-Regeneron; UCB, G. Burmester Grant/research support from: Roche, Consultant for: Roche DOI: 10.1136/annrheumdis-2017-eular.3312

\section{FRI0254 EFFICACY OF TOCILIZUMAB FOR SUPPRESSING RADIOGRAPHIC PROGRESSION OF CERVICAL LESIONS IN PATIENTS WITH RHEUMATOID ARTHRITIS COMPARISON WITH METHOTREXATE TREATMENT; TWO YEARS OF FOLLOW-UP $\sim$ A MULTICENTER REGISTRY STUDY}

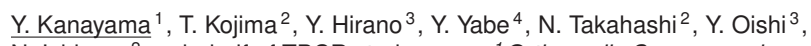
$\mathrm{N}$. Ishiguro ${ }^{2}$ on behalf of TBCR study group. ${ }^{1}$ Orthopedic Surgery and Rheumatology, Toyota Kosei Hospital, Toyota; ${ }^{2}$ Orthopedic Surgery, Nagoya University Graduate School of Medicine, Nagoya; ${ }^{3}$ Rheumatology, Toyohashi Municipal Hospital, Toyohashi; ${ }^{4}$ Rheumatology, Japan Community Healthcare Organization Tokyo Shinjuku Medical Center, Tokyo, Japan

Background: Cervical lesions are known to occur at high frequency as a complication of rheumatoid arthritis (RA). Treatment with biological agents are more clinically effective than the DMARDs that were in use previously, in particular, with their efficacy in suppressing joint destruction having been emphasized. We reported the efficacy of infliximab, anti-tumor necrosis factor antibodies for suppressing the radiographic progression of RA cervical lesions at ACR2009, EULAR2010, 11, 12, 13, 14 and 16. However there is still few studies of efficacy of against RA cervical lesions of Tocilizumab (TCZ), anti-interleukin 6 receptor antibody.

Objectives: To evaluate the efficacy of TCZ for suppressing the radiographic progression of RA cervical lesions comparison with MTX for 2 years.

Methods: We used TCZ or MTX for treating Japanese patients with active RA who fulfilled the ACR criteria in 1987. The final study cohort of each 38 and 71 patients received continuous TCZ and MTX treatment for at least 2 years. For evaluation of cervical lesions, the atlanto-dental interval (ADI), the space available for the spinal cord (SAC), and the Ranawat value were measured by plain lateral radiographs in the flexion position, at initiation and Year 1,2.

Results: In the patients receiving TCZ $(n=38)$ and MTX $(n=71)$, the number of female were each $28(72 \%)$ and $51(72 \%)$ cases $(p=0.999)$. The mean age was $57.3 \pm 12.4$ and $63.3 \pm 10.9$ years old $(p=0.011)$; disease duration was $7.0 \pm 7.3$ and $8.8 \pm 9.7$ years $(p=0.929)$ and the mean dose of MTX was $9.0 \pm 3.4$ and $8.3 \pm 2.9$ $\mathrm{mg} / \mathrm{w}(\mathrm{p}=0.335)$. Clinical findings related to RA were as follows; CRP $3.8 \pm 3.1$ and $1.5 \pm 2.1 \mathrm{mg} / \mathrm{dl}(\mathrm{p}<0.001)$; ESR $52.7 \pm 25.3$ and $30.0 \pm 20.8 \mathrm{~mm} / \mathrm{h}(\mathrm{p}<0.001)$; MMP3 $400 \pm 300$ and $213 \pm 356 \mathrm{ng} / \mathrm{ml}(p<0.001)$; the number of RF-positive $30(79 \%)$ and $58(82 \%)$ cases $(p=0.801)$; DAS28-ESR $5.46 \pm 0.92$ and $4.24 \pm 1.34(p<0.001)$; ADI $2.7 \pm 1.7$ and $2.6 \pm 1.6 \mathrm{~mm}(\mathrm{p}=0.917) ; \mathrm{SAC} 19.3 \pm 2.8$ and $20.7 \pm 2.5 \mathrm{~mm}(\mathrm{p}=0.008)$ and Ranawat value $15.4 \pm 1.6$ and $15.9 \pm 1.5 \mathrm{~mm}(p=0.073)$. The respective changes in cervical lesion parameters after 1 year were as follows: ADI: $0.21 \pm 0.53$ and $0.25 \pm 0.44 \mathrm{~mm}(\mathrm{p}=0.327) ; \mathrm{SAC}:-0.16 \pm 0.44$ and $-0.17 \pm 0.38 \mathrm{~mm}(\mathrm{p}=0.653)$; and Ranawat value: $-0.13 \pm 0.34$ and $-0.11 \pm 0.32 \mathrm{~mm}(p=0.773)$. The respective changes in cervical lesion parameters after 2 years were as follows: ADI: $0.32 \pm 0.70$ and $0.52 \pm 0.67 \mathrm{~mm}(\mathrm{p}=0.045)$; SAC: $-0.24 \pm 0.49$ and $-0.45 \pm 0.63 \mathrm{~mm}$ $(\mathrm{p}=0.067)$; and Ranawat value: $-0.24 \pm 0.49$ and $-0.35 \pm 0.56 \mathrm{~mm}(\mathrm{p}=0.270)$ in the patients receiving TCZ and MTX (Fig.1). The numbers of patients who did not

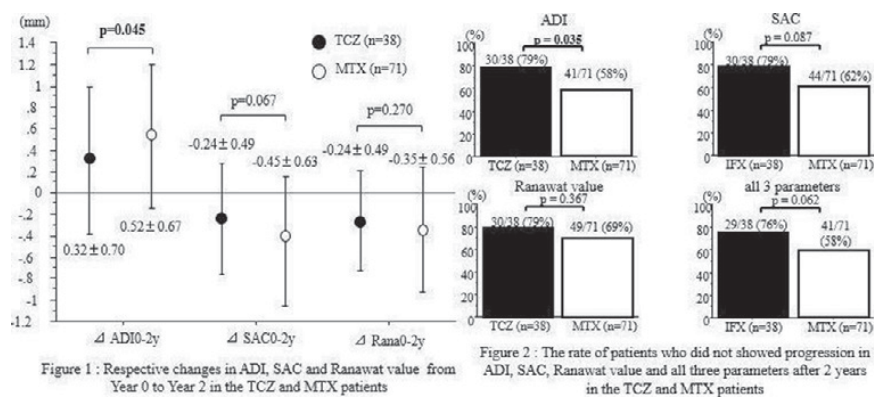

showed progression in ADI, SAC and Ranawat value were each $30(79 \%)$ and 41 $(58 \%)$ cases $(p=0.035) ; 30(79 \%)$ and $44(62 \%)$ cases $(p=0.087)$ and $30(79 \%)$ and $49(69 \%)$ cases $(p=0.367)$ after 2 years. Also the number who was able to suppress progression in all three parameters were each 29 cases $(76 \%)$ receiving TCZ and 41 cases (58\%) receiving MTX ( $\mathrm{p}=0.062)$ after 2 years (Fig.2).

Conclusions: This study suggested that TCZ treatment can be used to suppress the progression of RA cervical lesions more than MTX treatment.

Disclosure of Interest: None declared

DOI: 10.1136/annrheumdis-2017-eular.4698

\section{FRIDAY, 16 JUNE 2017}

\section{SLE, Sjögren's and APS - clinical aspects (other than treatment)}

\section{FRI0255 PATTERNS OF DISEASE ACTIVITY IMPACT ON ORGAN DAMAGE IN SYSTEMIC LUPUS ERYTHEMATOSUS}

A. Bortoluzzi, M. Padovan, E. Silvagni, C.A. Scirè, M. Govoni. Department of Medical Sciences, Rheumatology Unit, University of Ferrara and Azienda Ospedaliero-Universitaria Sant'Anna, Cona (Ferrara), Italy

Background: Systemic lupus erythematosus (SLE) is a multisystem autoimmune disease characterized by fluctuating disease activity in which adverse long-term outcomes remain a major challenge. In the face of extreme individual unpredictability of the disease course over time, four different patterns can be defined, as elsewhere described [1], using SLEDAl-2K (Systemic Lupus Erythematosus Disease Activity Index-2K) excluding serology in order to focus on clinical activity. The patterns are clinical quiescent disease (CQD), chronic active disease (CAD), relapsing-remitting disease (RRD) and minimal disease activity (MDA).

Objectives: The aim of our study was to assess the association between different disease activity patterns and damage accrual in SLE patients.

Methods: Patients with SLE registered at our Lupus Clinic at the Rheumatology Unit, between 1 January 2013 and 1 October 2016, were included. Demographic and clinical variables included age, gender, age at SLE onset, major organ involvement. SDI (Systemic Lupus International Collaborating Clinics/American College of Rheumatology (SLICC/ACR) Damage Index) was categorized as absent $(S D I=0)$ or present $(S D I \geq 1)$, Disease activity patterns (CQD, MDA, RRD, CAD) were retrospectively assessed. Drugs used in the treatment of SLE, including hydroxychloroquine, cumulative dose of glucocorticoid (prednisone equivalent $>10 \mathrm{~g}$ ) and other immunosuppressive drugs, were also collected. Multivariate logistic regression analyses were performed to identify disease patterns associated with damage accrual. Results are presented as odds ratio (OR) and $95 \%$ confidence intervals $(\mathrm{Cl})$.

Results: A total of 473 Caucasian patients were observed, mainly female $(89.4 \%$ $\mathrm{F}, 10.6 \% \mathrm{M})$, mean age 52.6 years $( \pm 14.9 \mathrm{SD})$. In our cohort, the disease activity pattern distribution was as follows: $65.4 \%$ CQD (290 pts), 21.5\% RRD (91 pts), $6.1 \%$ MDA (28 pts) and CAD in $19.1 \%$ of the cases (64 pts). Damage was significantly more frequent in CAD subset $(81.2 \%, 52 / 64 \mathrm{pts})$ versus $54.5 \%$ in $C Q D$ (158/290 pts), $50 \%$ in MDA (14/28 pts) and 58.2\% in RRD (53/91 pts). Compared to a CQD course, CAD pattern was independently associated with overall damage after controlling for factors including gender, disease duration, cumulative glucocorticoid dosage, major individual organ involvement (neuropsychiatric and renal), positive antiphospholipid antibody profile, exposures to cyclophosphamide and hydroxychloroquine (Table 1).

Table1. Logistic regression analysis of independent factors associated with damage in SLE patient

\begin{tabular}{|c|c|c|c|c|}
\hline Factors & $\begin{array}{l}\text { Crude odds ratio } \\
(95 \% \mathrm{Cl})\end{array}$ & P value & $\begin{array}{l}\text { Adjusted" Odds ratio } \\
(95 \% \mathrm{Cl})\end{array}$ & $P$ value \\
\hline \multicolumn{5}{|l|}{ Disease Activity Pattern } \\
\hline Clinical quiescent disease & Reference category & & Reference category & \\
\hline Minimal disease activity & $0.84(0.38 \cdot 1.81)$ & 0.650 & $0.77(0.33 \cdot 1.80)$ & 0.541 \\
\hline Relapsing-remitting disease & $1.16(0.73 \cdot 1.87)$ & 0.529 & $1.03(0.62 \cdot 1.72)$ & 0.900 \\
\hline Chronic active disease & $3.62(1.86 \cdot 7.07)$ & $<0.0001$ & $3.07(1.49 \cdot 6.34)$ & 0.002 \\
\hline Gender (M) & $1.23(0.68 \cdot 2.22)$ & 0.489 & $1.29(0.68 \cdot 2.43)$ & 0.434 \\
\hline Disease duration(yr) & $1.05(1.03 \cdot 1.07)$ & $<0.0001$ & $1.03(1.01-1.06)$ & 0.033 \\
\hline NP involvement & $2.86(1.65 \cdot 4.94)$ & $<0.0001$ & $2.11(1.17 \cdot 3.80)$ & 0.013 \\
\hline Renal involvement & $1.35(0.76 \cdot 2.41)$ & 0.301 & $0.95(0.49 \cdot 1.84)$ & 0.877 \\
\hline aPL positivity & $1.68(1.16 \cdot 2.44)$ & 0.006 & $1.64(1.09 \cdot 2.47)$ & 0.017 \\
\hline $\begin{array}{l}\text { Cumulative dosage of CS } \\
\text { (>10g PDN) }\end{array}$ & $2.50(1.69 \cdot 3.71)$ & $<0.0001$ & $1.64(1.03 \cdot 2.61)$ & 0.038 \\
\hline $\mathrm{HCO}$ & $0.37(0.24 \cdot 0.57)$ & $<0.0001$ & $0.41(0.26 \cdot 0.66)$ & $<0.0001$ \\
\hline $\mathrm{CYC}$ & $2.46(0.97 \cdot 6.25)$ & 0.058 & $1.89(0.66 \cdot 5.46)$ & 0.236 \\
\hline
\end{tabular}

* adjusted for: age, gender, disease duration, NP and renal involvement, cumulative dosage of CS; aPL positivity, HCQ CYC (NP, neuropsychiatric; aPL, antiphosphlipid; CYC, cyclophosphamide; HCQ hydroxychloroquine; $M$, male; $C$, corticosteroid; PDN, prednisone) 